\title{
Enhanced Photoelectrochemical Properties of Fe-TiO 2 Nanotube Films: A Combined Experimental and Theoretical Study
}

\author{
Yanfeng Zhu
}

Department of Chemical Engineering and Safety, Binzhou University, Binzhou, Shandong 256603, PR China

E-mail: yanfengzhu2014@163.com

doi: $10.20964 / 2021.06 .65$

Received: 25 February 2021 / Accepted: 15 April 2021 / Published: 30 April 2021

Fe-doped $\mathrm{TiO}_{2}$ nanotube array $\left(\mathrm{Fe}-\mathrm{TiO}_{2} \mathrm{TNTA}\right)$ films are produced by a simple and facile anodization method on Ti foil substrates. The Fe-doped TNTA films were characterized by SEM, Raman, XPS and UV-vis spectrum. The result showed that the absorption edge generated bathochromic shift. Raman and XPS reveal that $\mathrm{Ti}^{4+}$ ions were uniformly substituted by $\mathrm{Fe}^{3+}$ ions or $\mathrm{Ti}-\mathrm{O}-\mathrm{Fe}$ bonds. After comparing different $\mathrm{Fe}^{3+}$ ions concentrations, $0.1 \mathrm{M} \mathrm{Fe}$-doped $\mathrm{TiO}_{2}$ samples exhibite the highest photocurrent value, indicating super photoelectrochemical activity. The difference between the photocathodic protection properties of TNTA films and Fe-doped TNTA films is also investigated. The The density functional theory (DFT) calculation is carried out to confirm the effects of the $\mathrm{Fe}^{3+}$ ions on the absorption edge redshift and the bandgap changes.

Keywords: $\mathrm{TiO}_{2}$ nanotube arrays; Fe-doped; Photoelectrochemical; EIS; DFT calculations;

\section{$\underline{\text { FULL TEXT }}$}

(C) 2021 The Authors. Published by ESG (www.electrochemsci.org). This article is an open access article distributed under the terms and conditions of the Creative Commons Attribution license (http://creativecommons.org/licenses/by/4.0/). 